\title{
Risk Factors, Clinical Characteristics, and Outcome of Air Leak Syndrome in COVID-19: A Systematic Review
}

\author{
Abhishek Singh $^{1} \odot$, Yudhyavir Singh ${ }^{\infty}$, Neha Pangasa $^{3} \odot$, Puneet Khanna ${ }^{4}$, Anjan Trikha ${ }^{5}$
}

\begin{abstract}
Introduction: Air leak consisting of pneumothorax, pneumomediastinum, and subcutaneous emphysema has been described as one of the complications of coronavirus disease-2019 (COVID-19) infection affecting disease course and outcome. We aimed to conduct a systematic review of published literature to highlight the risk factors, types, and outcomes in COVID-19.

Method: A systematic search of PubMed, Embase, Scopus, and Google Scholar was performed from November 1, 2019 , to February $28,2021$. Seventy-one studies fulfilled the inclusion criteria and 136 adult patients were included in the final analysis.

Results: Majority of patients were male (75.2\%) with the mean age of 58 years. Hypertension was the most common comorbidity followed by diabetes mellitus. Moreover, $12.5 \%$ of patients had a history of smoking while $11.7 \%$ had preexisting lung disease. Isolated pneumothorax $(48.5 \%)$ was the most common and $17.65 \%$ had developed spontaneous pneumothorax. Mean onset time was 11.6 days and $67 \%$ of patients required an intercostal drainage tube for management. Mortality was $40 \%$, and elderly, female gender, obese and hypertensive were at higher risk. Conclusion: COVID-19-related air leaks are associated with higher mortality and longer hospital stay and can occur even without positive pressure ventilation. History of smoking and preexisting lung disease has not been shown to increase the incidence of air leak. A well-designed study is required for a better understanding of COVID-19-related air leak.

Keywords: Air leak, COVID-19, Pneumomediastinum, Pneumothorax, Subcutaneous emphysema.

Indian Journal of Critical Care Medicine (2021): 10.5005/jp-journals-10071-24053
\end{abstract}

\section{INTRODUCTION}

Coronavirus disease-2019 (COVID-19) generally presents as a multisystem disease but the lung is the most affected organ. Respiratory complications associated with the disease range from self-limited upper respiratory infection presenting as fever, dry cough, fatigue, headache, and body pain to acute respiratory failure and air leak syndrome comprising of pneumothorax, pneumomediastinum, and subcutaneous emphysema requiring mechanical ventilation and pleural drainage. ${ }^{1}$ When supplemental oxygen therapies with nasal prongs and face mask are insufficient to maintain the desired oxygen saturation in respiratory failure due to COVID-19, higher forms of respiratory support like highflow nasal cannula (HFNC), continuous positive airway pressure (CPAP), noninvasive ventilation like bilevel PAP (BiPAP), and invasive mechanical ventilation are required. Pneumothorax, pneumomediastinum, and subcutaneous emphysema are collectively called as air leak syndrome that has a reported incidence of up to $15 \%$ in critically ill non-COVID patients requiring mechanical ventilation. ${ }^{2}$ Various studies have reported the incidence of COVID-19 related barotrauma to be around $1-2 \%$ in hospitalized patients. ${ }^{3,4}$ However, many patients with COVID-19 have also developed spontaneous air leak that warranted close observation and timely intervention. A combination of factors like COVID-19 induced lung frailty, increased intrathoracic pressure due to mechanical ventilation, and persistent coughing has been implicated as the causative factor for COVID-19-associated air leak. We aimed to conduct a systematic review of the available literature on the occurrence of pneumothorax, pneumomediastinum, and subcutaneous emphysema in COVID-19 patients with an emphasis to evaluate the risk factors, strategies of its management, and effect of the above-mentioned complications on patient survival.
${ }^{1}$ All India Institute of Medical Sciences, New Delhi, India

${ }^{2-4}$ Department of Anaesthesiology, Critical Care and Pain Medicine, All India Institute of Medical Sciences, New Delhi, India

${ }^{5}$ Department of Anaesthesiology, All India Institute of Medical Sciences, New Delhi, India

Corresponding Author: Yudhyavir Singh, Department of Anaesthesiology, Critical Care and Pain Medicine, All India Institute of Medical Sciences, New Delhi, India, Phone: +91 9811140057, e-mail: yudhyavir@gmail.com

How to cite this article: Singh A, Singh $Y$, Pangasa N, Khanna $P$, Trikha A. Risk Factors, Clinical Characteristics, and Outcome of Air Leak Syndrome in COVID-19: A Systematic Review. Indian J Crit Care Med 2021;25(12):1434-1445.

Source of support: Nil

Conflict of interest: None

\section{Methods}

This systematic review was conducted and presented in accordance with Preferred Reporting Items for Systematic Reviews and Meta-Analyses (PRISMA) guidelines. Ethics committee approval and informed consent from the patient were not required as it is a systematic review of already published literature on COVID-19.

\section{Search Strategy}

A comprehensive literature search was made from PubMed, Embase, Scopus, and Google Scholar using keywords like "pneumothorax", "pneumomediastinum", "subcutaneous emphysema", "barotraumas", "COVID-19", "SARS-CoV-2", and

(c) The Author(s). 2021 Open Access This article is distributed under the terms of the Creative Commons Attribution 4.0 International License (https://creativecommons. org/licenses/by-nc/4.0/), which permits unrestricted use, distribution, and non-commercial reproduction in any medium, provided you give appropriate credit to the original author(s) and the source, provide a link to the Creative Commons license, and indicate if changes were made. The Creative Commons Public Domain Dedication waiver (http://creativecommons.org/publicdomain/zero/1.0/) applies to the data made available in this article, unless otherwise stated. 
"coronavirus-2" from November 2019 to February 2021. All the above-mentioned keywords were using the "OR" and "AND" operator for searching the databases.

\section{Inclusion Criteria}

Articles fulfilling the following set criteria were included in our study-firstly, articles that described pneumothorax, pneumomediastinum, or subcutaneous emphysema and their associated pathophysiology as well as their management in adult (age $>18$ years) COVID-19 patients, secondly, studies published in the English language, and third, published between November 1, 2019, and February 28, 2021.

\section{Exclusion Criteria}

Studies lacking detailed information regarding COVID-19 associated air leak and not having patient-specific data were excluded.

\section{Data Extraction}

After screening the articles, data were extracted by two authors (AS and NP) independently. Any disparity among data was resolved by discussion with the third researcher (YS). Details about the author, type of study, number of patients, age, gender, the onset of barotrauma, type of barotraumas, respiratory support, treatment given, duration of stay, comorbidities, history of smoking, and outcome were extracted and presented in designed data extraction table (Table 1).

\section{Statistical Analysis}

The statistical analysis was performed using strata (New York). The continuous variables were expressed as mean \pm standard deviation while categorical variables were expressed as a percentage. The Student $t$-test was used for continuous variables and Chi-square or Fisher's exact test for categorical variables. The $p$-value less than 0.05 was considered statistically significant.

\section{Results}

\section{Study Selection}

A total of 205 studies were identified for possible inclusion in the study. After the removal of duplicates (85) and articles with inadequate information and those not meeting our inclusion criteria (49), 71 articles were included in our review. A detailed PRISMA diagram about the search strategy and included studies are mentioned in Flowchart 1.

\section{Demographic Characteristics of Patients}

A total of 136 patients from 71 studies were included in this review. The proportion of male patients was $75.2 \%$ and female was $24.8 \%$ (Table 2). The mean age of the patients was 58.44 years with the youngest patient was of age 26 years reported by Rohailla et al. ${ }^{5}$ and eldest of age 88 years reported by Sardenberg et al. ${ }^{6} \mathrm{~A}$ total of 9 comorbidities were reported by authors from 52 included studies and some have reported more than one comorbidity in single patients (Table 1 and Fig. 1). The comorbidities consisted of diabetes mellitus, hypertension, obesity, chronic obstructive pulmonary disease (COPD), asthma, coronary artery disease, chronic liver disease, and chronic kidney disease. The most common was hypertension followed by diabetes mellitus. Moreover, $30.8 \%$ of patients reported no comorbidities while $14.7 \%$ had not mentioned of comorbidities in the published studies. The history of smoking was observed in $12.5 \%$ of the patient.

\section{Characteristics of COVID-19-associated Air Leak Type}

Isolated pneumothorax, pneumomediastinum, and subcutaneous emphysema were present in $48.5,3.6$, and $1.4 \%$ of patients, respectively. All three were present in $15.4 \%$ of patients, $12.5 \%$ had pneumothorax and pneumomediastinum, $8 \%$ had pneumomediastinum and subcutaneous emphysema, and $6.6 \%$ had pneumothorax and subcutaneous emphysema (Table 2 and Fig. 2).

\section{Respiratory Support}

Patients have presented to the hospital in different forms of respiratory support ranging from spontaneously breathing at room air to mechanical ventilation. Most commonly patients were presented on room air (19.9\%), followed by HFNC (12.5\%) and it was not mentioned in $37.50 \%$. Respiratory support at time of air leak too varied from room air to mechanical ventilation. Patient on

Flowchart 1: PRISMA flow diagram of search strategy

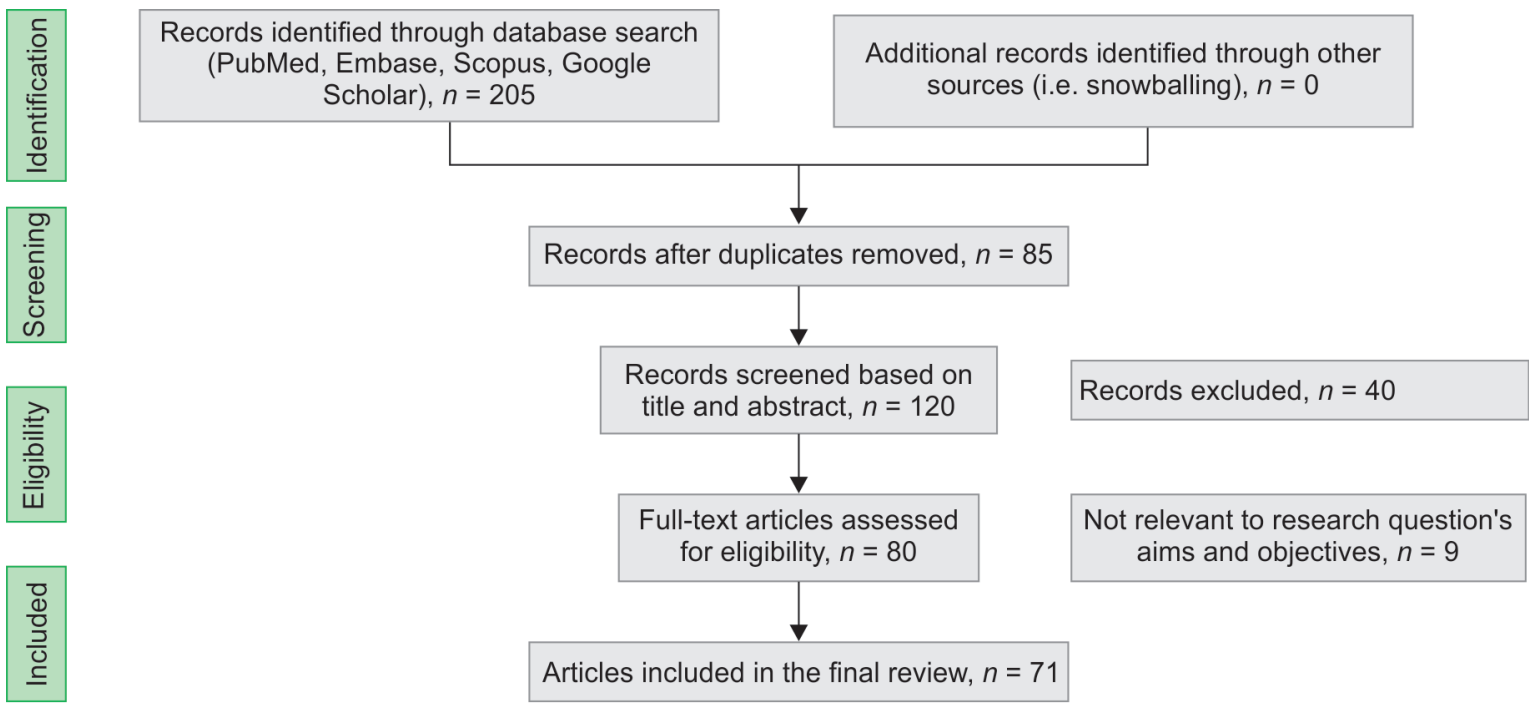




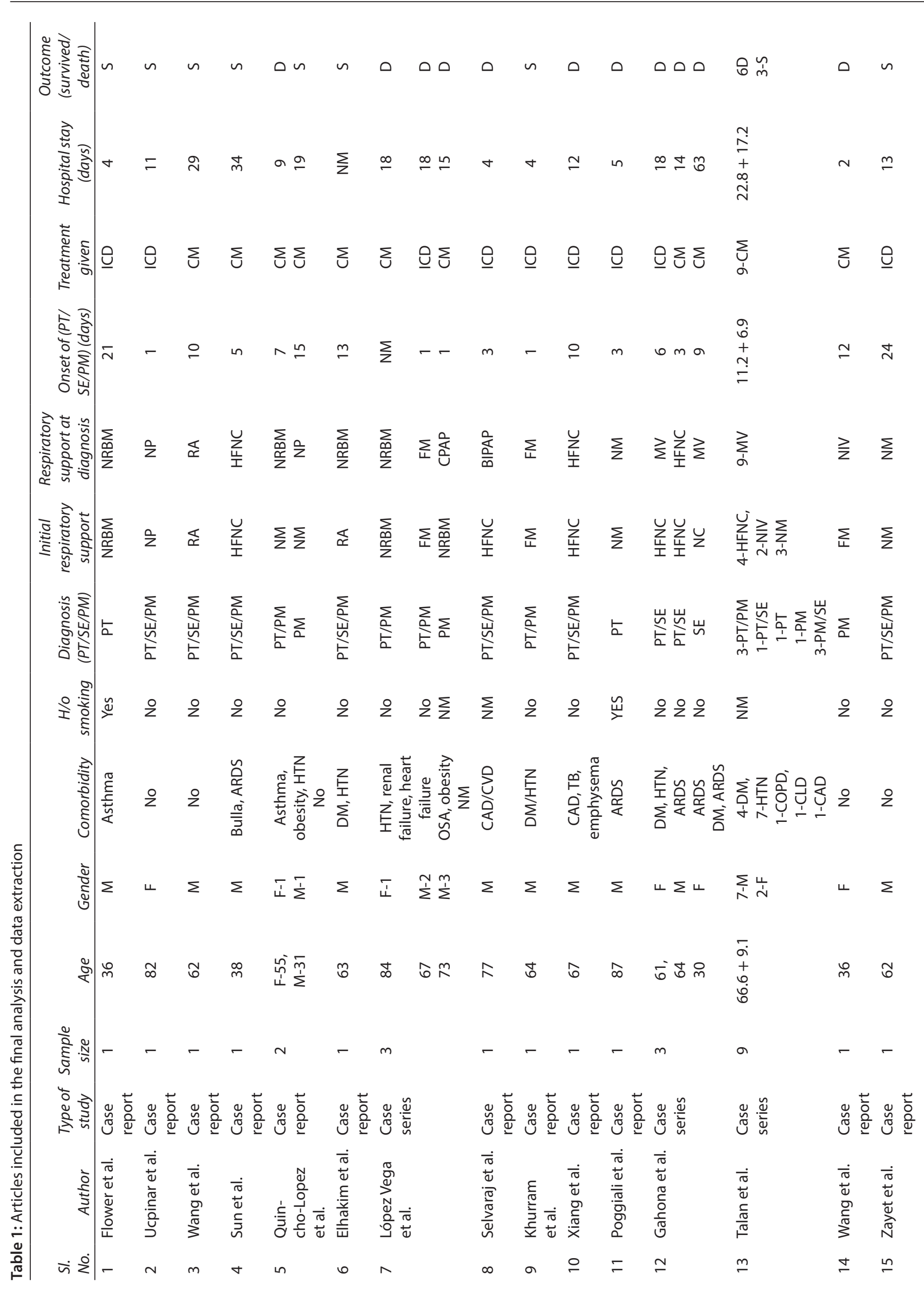




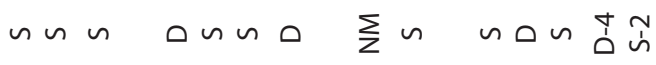

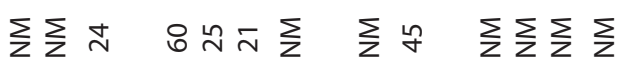

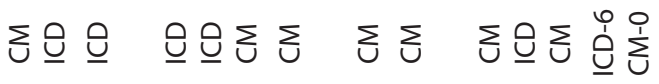

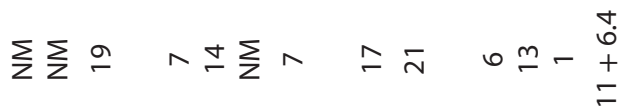

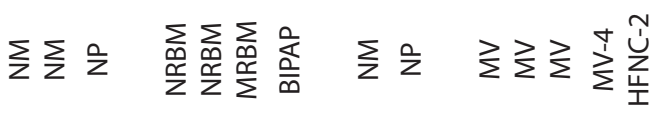

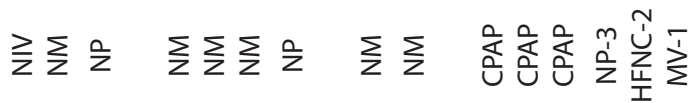

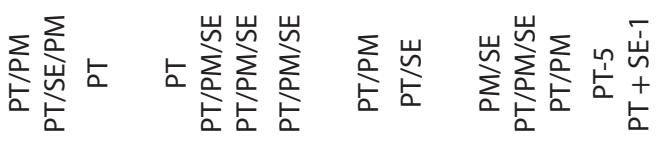

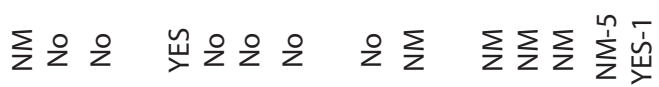

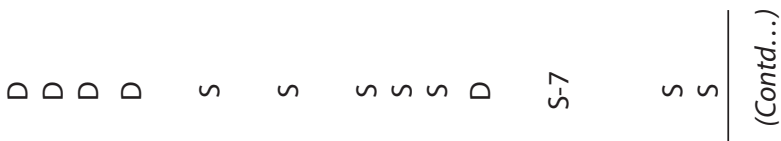

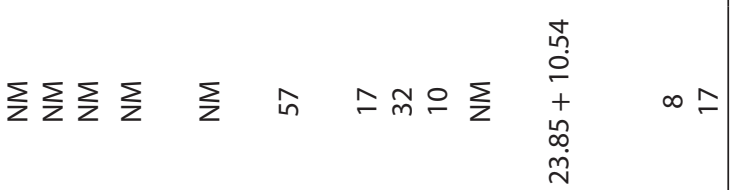

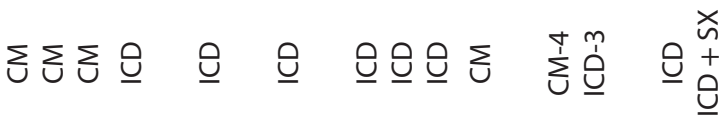

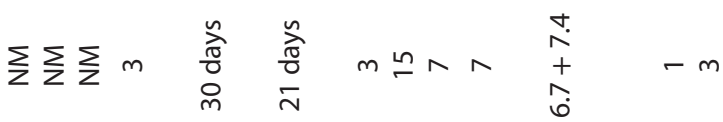

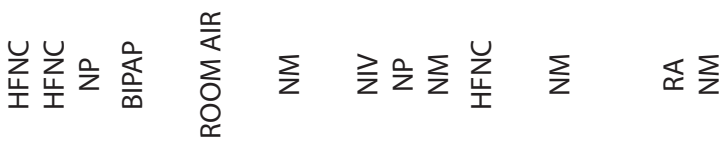

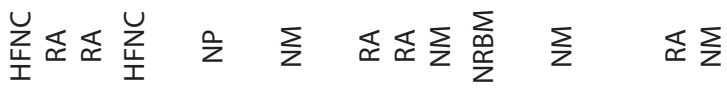

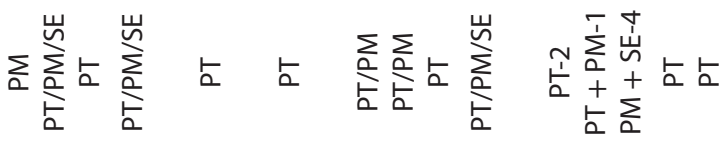

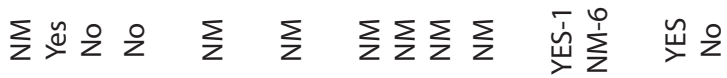

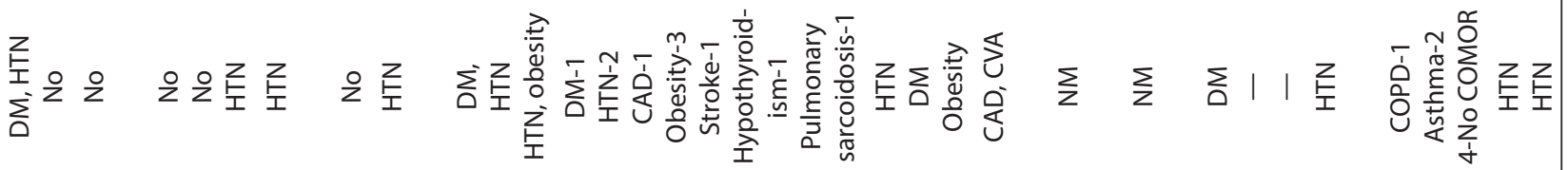

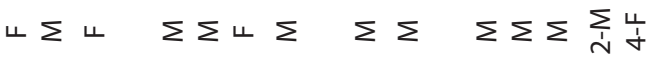
$\sqcup \Sigma \Sigma \Sigma \sum \Sigma \sum_{m} \sum \sum \sum \sqcup$ パチ タ

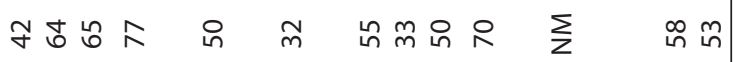

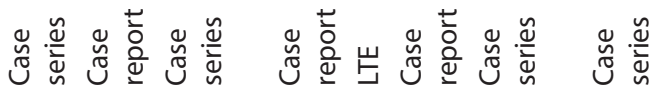

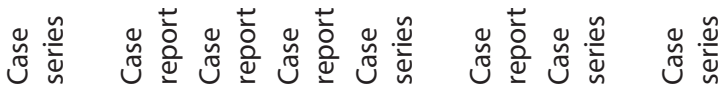

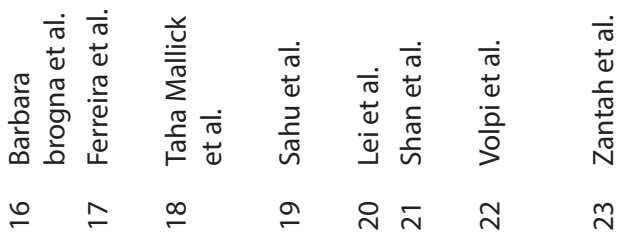




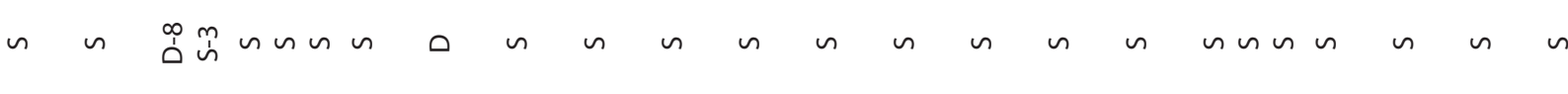

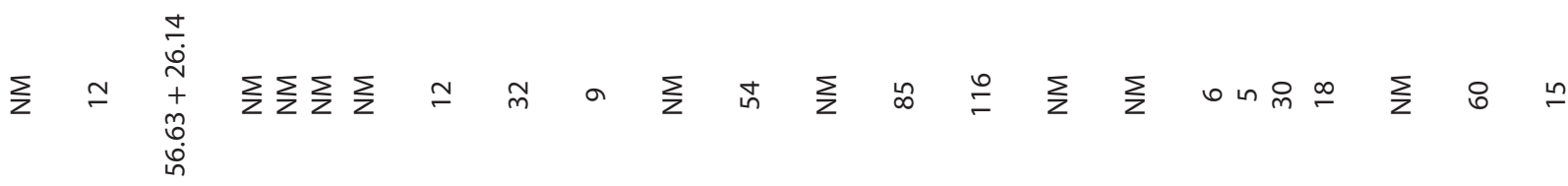

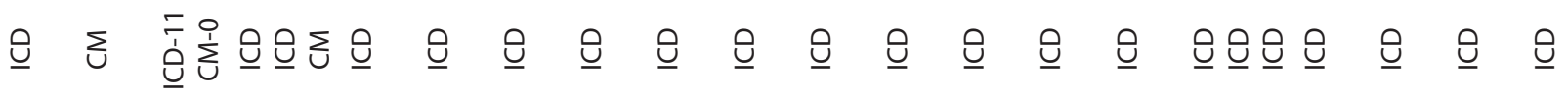

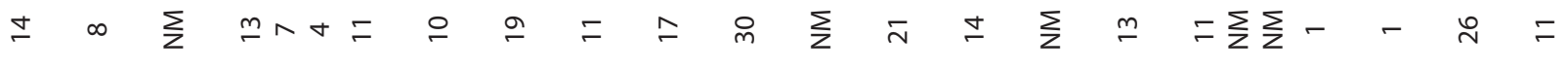

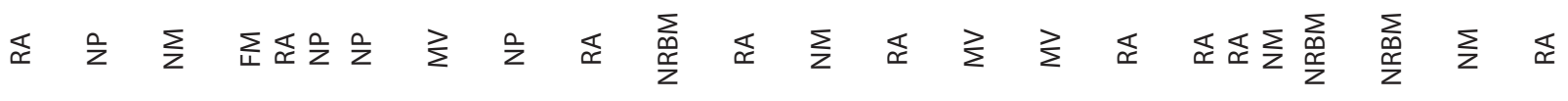

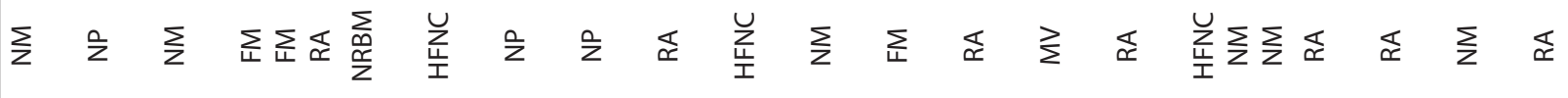

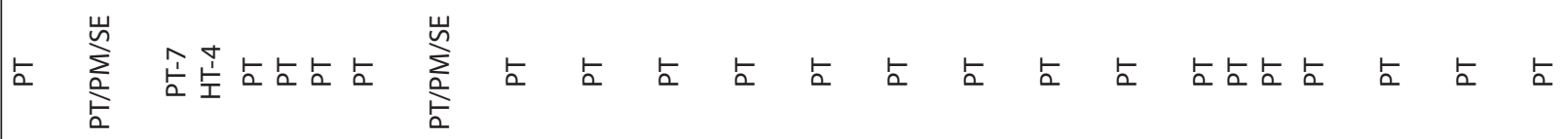

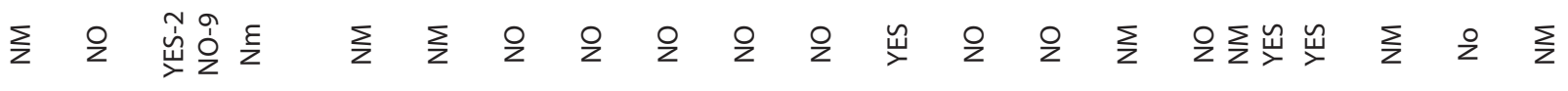

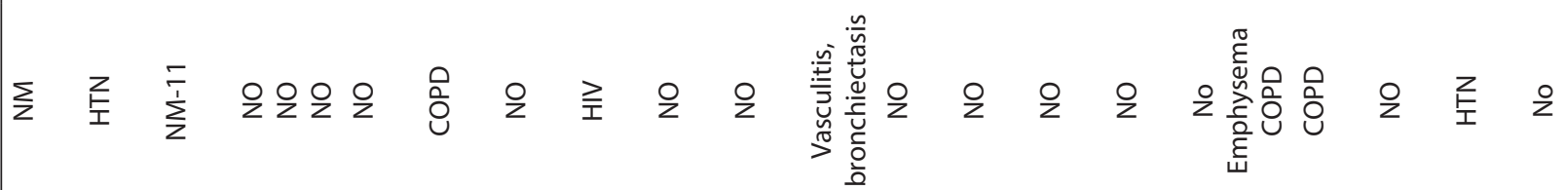

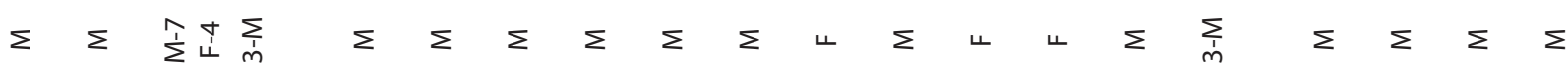

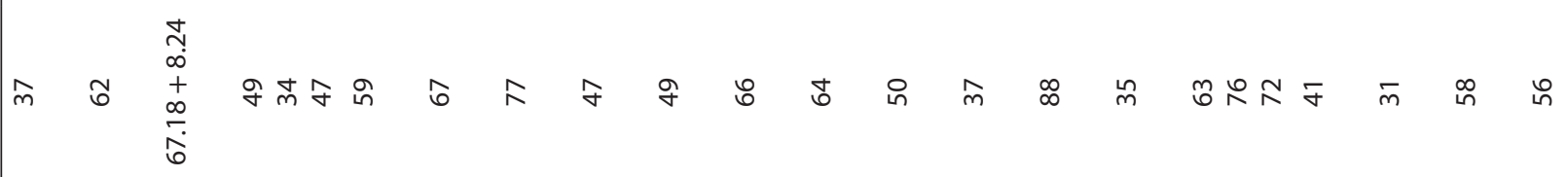

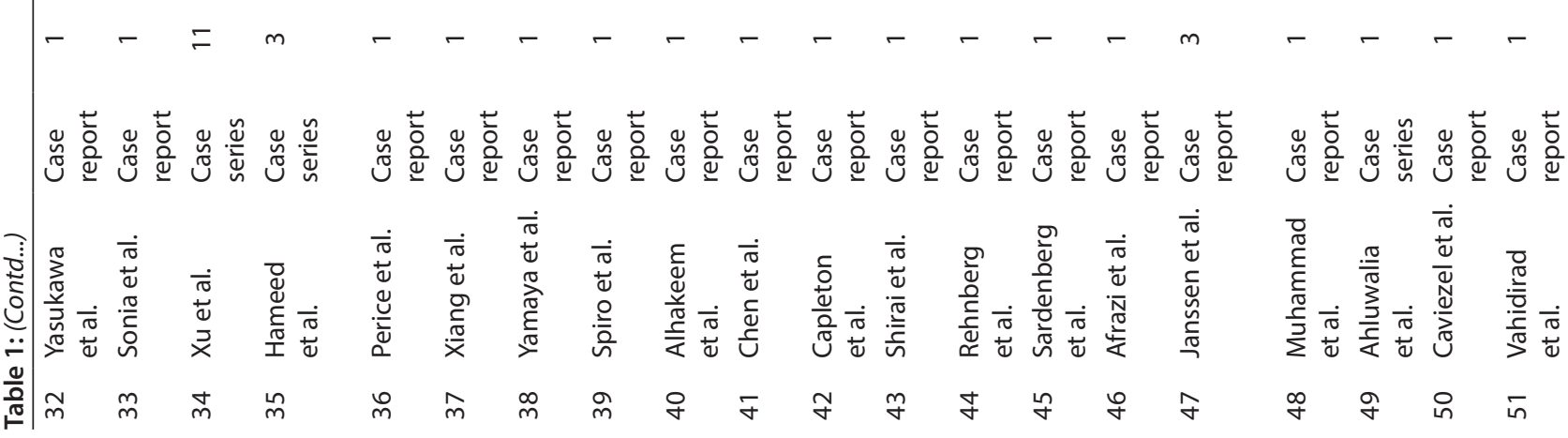




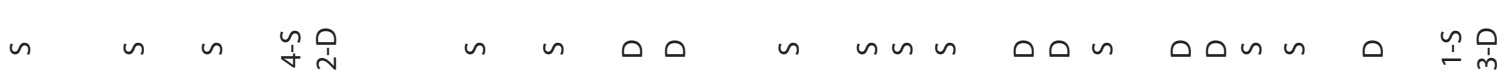

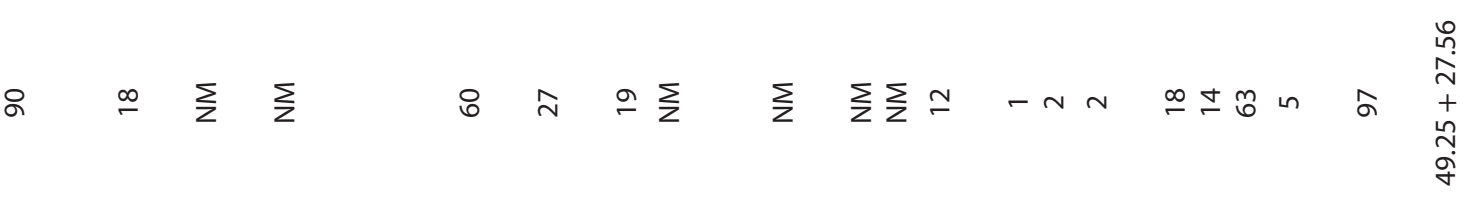

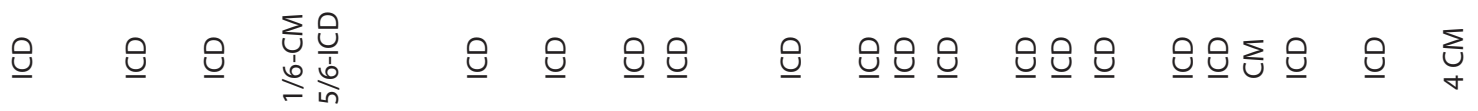

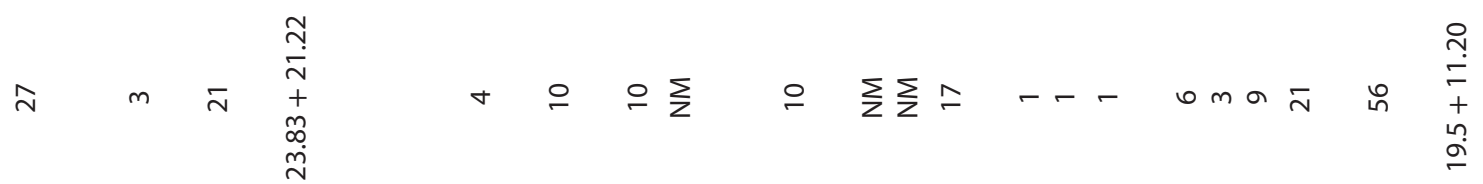

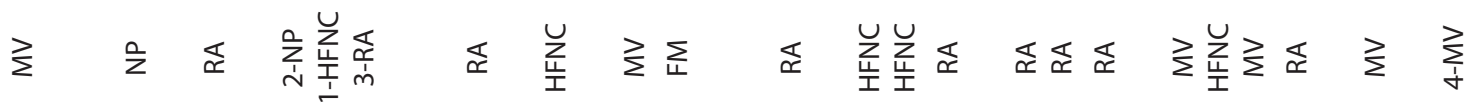

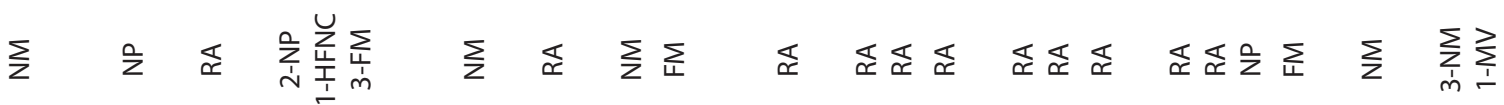

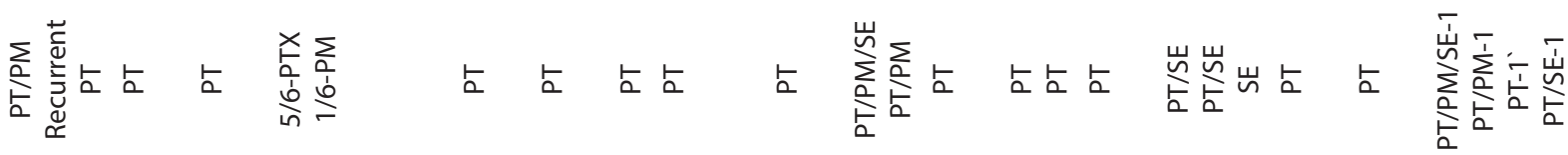

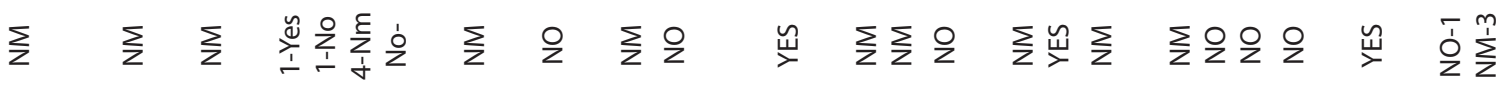

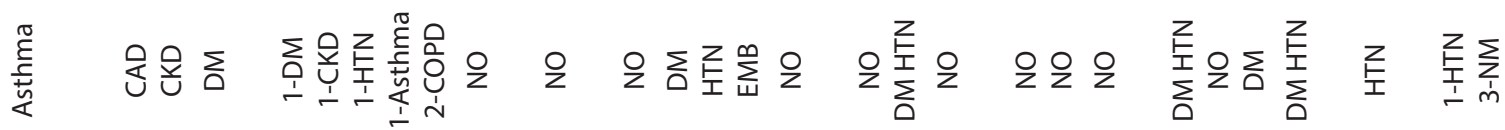

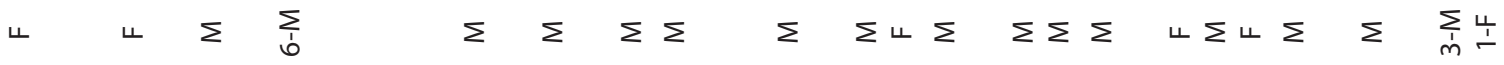

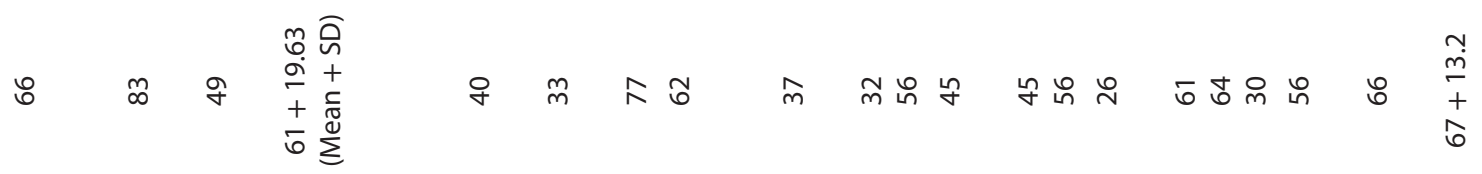

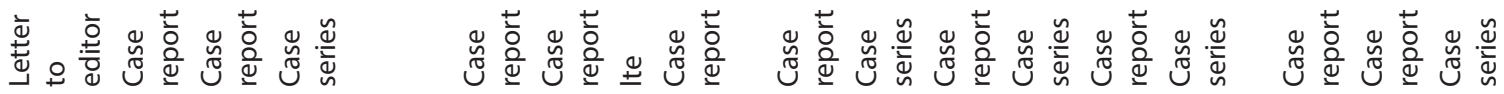

\begin{tabular}{|c|c|c|c|c|c|c|c|c|c|}
\hline 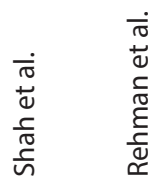 & 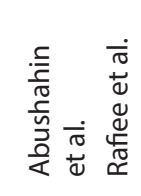 & 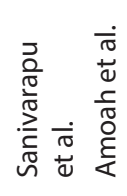 & 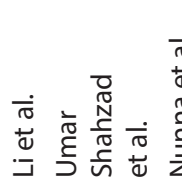 & 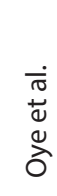 & 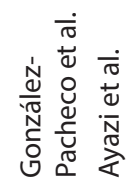 & 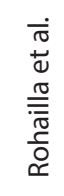 & $\begin{array}{l}\dot{0} \\
\frac{\pi}{0} \\
0 \\
\tilde{0} \\
\tilde{0} \\
\frac{0}{\pi} \\
\frac{\pi}{0}\end{array}$ & $\begin{array}{l}\dot{0} \\
\frac{\pi}{0} \\
\frac{0}{0} \\
\frac{\pi}{\pi} \\
\frac{\pi}{\omega}\end{array}$ & $\begin{array}{l}\dot{\sigma} \\
+\frac{0}{0} \\
: \bar{\Xi} \\
\text { 온 }\end{array}$ \\
\hline in & 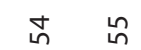 & 뉴 & $\stackrel{\circ}{\circ}$ in & $\overline{6}$ & $\widetilde{\sigma}$ & & & 8 & 6 \\
\hline
\end{tabular}




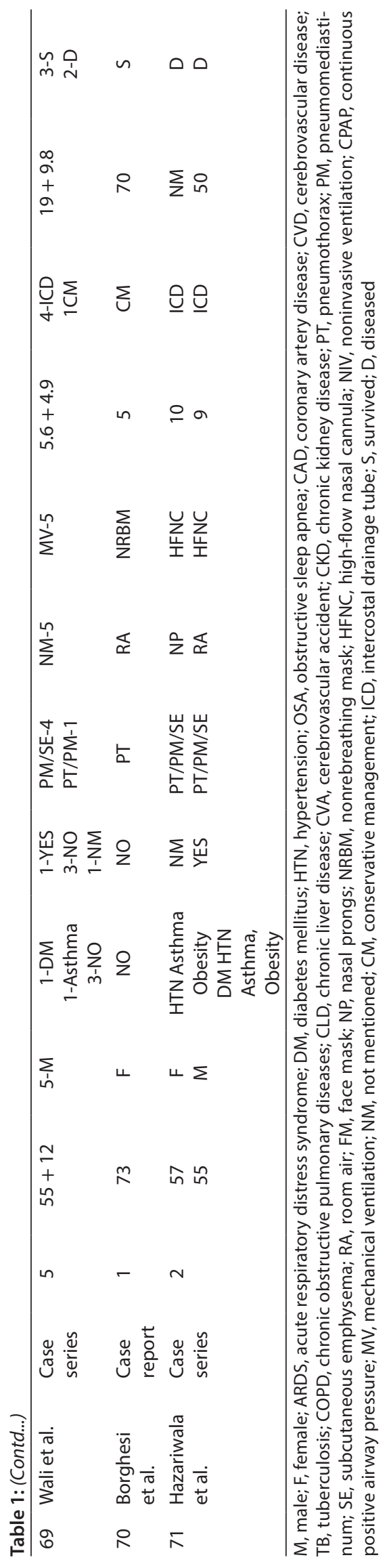

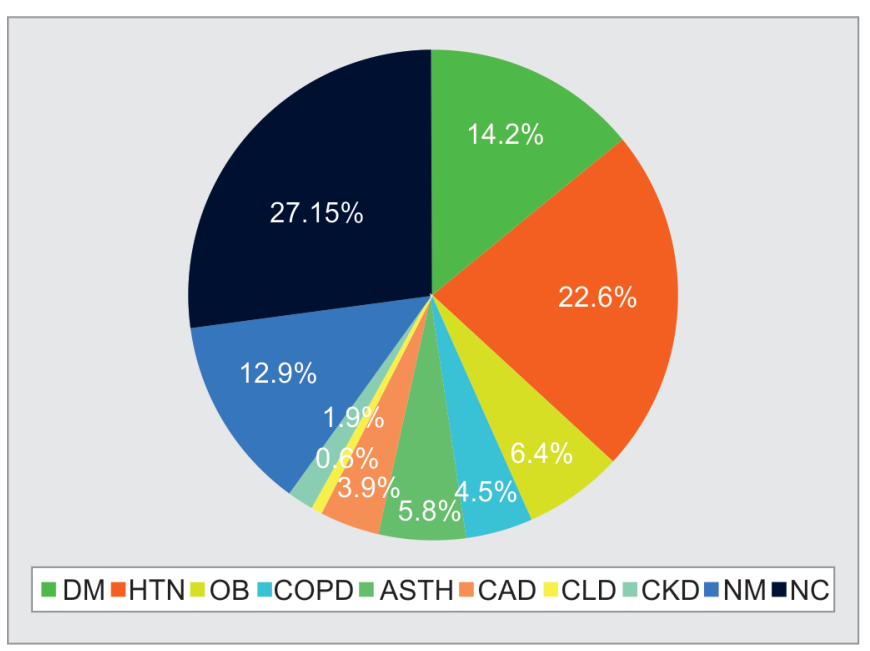

Fig. 1: Relative proportion of comorbidities among included patients

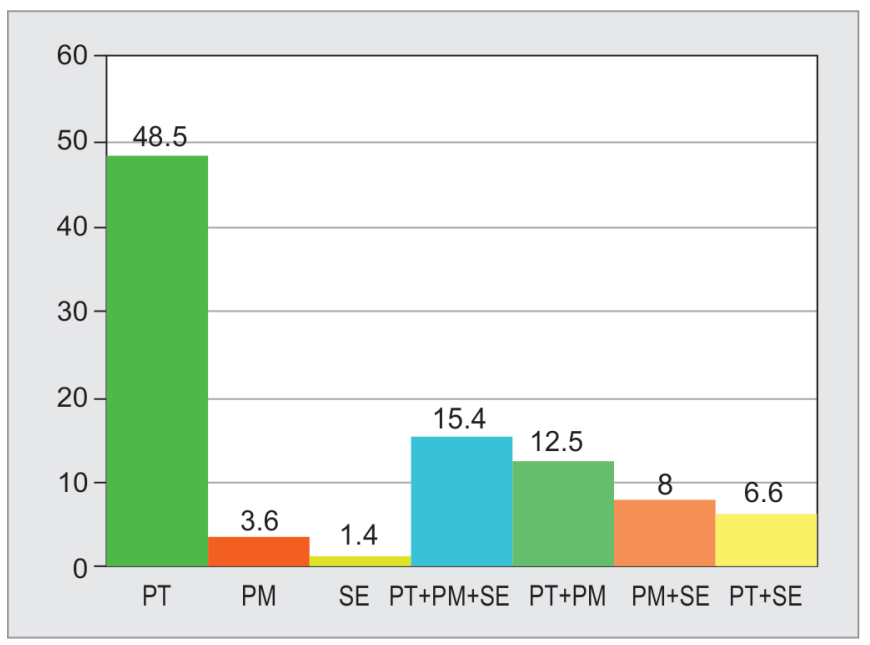

Fig. 2: Relative proportion of type of air leak

mechanical ventilation has the highest incidence of pneumothorax (25.74\%) and $17.65 \%$ of patients have reported the development of spontaneous pneumothorax. Occurrence of air leak in other modalities of respiratory support was HFNC (11\%), NRBM (8.1\%), NP (9.56\%), NIV and CPAP (3.69\%), and FM (3.68\%) (Table 3 and Fig. 3).

Onset

The mean time for diagnosis of pneumothorax was 11.63 days. Some studies have reported the presence of pneumothorax at the time of first contact with healthcare facility ${ }^{7-13}$ while others have reported its development as late as 56 days $^{14}$ from the onset of symptoms (Table 1 and Fig. 4).

\section{Treatment}

Conservative management was given in $33 \%$ of the patients while $67 \%$ of the patients required intercostal drainage tube for air leak. Data regarding medical management of COVID-19 have not been uniformly reported across studies.

Outcome

The overall mortality in COVID-19 patients with air leak was $40 \%$. COVID-19 patients with age more than 60 years, female gender, 
Air Leak in COVID-19

Table 2: Demographic and clinical characteristics of COVID-19 associated air leak

\begin{tabular}{|c|c|c|c|c|}
\hline Characteristics & Overall (N-136) & Survivor (N-81/135) & Diseased (54/135) & $p$ value \\
\hline Age (years) & $58.44 \pm 14.93$ & $54.40 \pm 14.92$ & $63.87 \pm 87$ & 0.0003 \\
\hline Male & 97 (75.78\%) & 60 (62.5\%) & $36(37.5 \%)$ & 0.04 \\
\hline Female & 32 (24.22\%) & $14(43.7 \%)$ & $18(56.25 \%)$ & \\
\hline \multicolumn{5}{|l|}{ Comorbidity } \\
\hline Diabetes & $22(16.2 \%)$ & $11(50 \%)$ & $11(50 \%)$ & 0.20 \\
\hline Hypertension & $35(25.7 \%)$ & $16(45.7 \%)$ & $19(54.3 \%)$ & 0.03 \\
\hline Obesity & $10(7.3 \%)$ & $3(30 \%)$ & $7(70 \%)$ & 0.04 \\
\hline COPD & $7(5.1 \%)$ & $4(57.1 \%)$ & $3(42.9 \%)$ & 0.58 \\
\hline Asthma & $9(6.6 \%)$ & $5(55.5 \%)$ & $4(44.5 \%)$ & 0.51 \\
\hline CAD & $6(4.4 \%)$ & ** & $* *$ & ${ }^{* *}$ \\
\hline CLD & $1(0.7 \%)$ & ** & ** & ** \\
\hline CKD & $3(2.2 \%)$ & ** & $* *$ & ** \\
\hline Smoking & $17(12.5 \%)$ & $10(58.2 \%)$ & $7(41.8 \%)$ & 0.44 \\
\hline No comorbidities & $42(30.8 \%)$ & $34(80.9 \%)$ & $8(19.1 \%)$ & 0.0006 \\
\hline NM & $20(14.7 \%)$ & $* *$ & $* *$ & ** \\
\hline \multicolumn{5}{|c|}{ Characteristics of PT/SE/PM } \\
\hline Onset & $11.63 \pm 10.30$ & $12.30 \pm 10.45$ & $10.39 \pm 10.16$ & 0.24 \\
\hline PT & $66(48.5 \%)$ & 45 (68.2\%) & $21(31.8 \%)$ & 0.04 \\
\hline PM & $5(3.6 \%)$ & $3(60 \%)$ & $2(40 \%)$ & $* *$ \\
\hline SE & $2(1.4 \%)$ & $1(50 \%)$ & $1(50 \%)$ & ** \\
\hline $\mathrm{PT}+\mathrm{PM}+\mathrm{SE}$ & $21(15.4 \%)$ & $11(52.30 \%)$ & $10(47.7 \%)$ & 0.29 \\
\hline $\mathrm{PT}+\mathrm{PM}$ & $17(12.5 \%)$ & $9(52.9 \%)$ & $8(47.1 \%)$ & 0.35 \\
\hline $\mathrm{PM}+\mathrm{SE}$ & $11(8 \%)$ & $9(81.8 \%)$ & $2(18.2 \%)$ & 0.10 \\
\hline $\mathrm{PT}+\mathrm{SE}$ & $9(6.6 \%)$ & $3(33.3 \%)$ & $6(66.7 \%)$ & 0.09 \\
\hline \multicolumn{5}{|l|}{ Treatment given } \\
\hline $\mathrm{CM}$ & $44(33 \%)$ & $24(54.5 \%)$ & $20(45.5 \%)$ & 0.23 \\
\hline ICD & $92(67 \%)$ & $57(62 \%)$ & $34(38 \%)$ & 0.19 \\
\hline Duration of stay & $31.27 \pm 25.68$ & $32.83 \pm 26.85$ & $29.07 \pm 24.11$ & 0.61 \\
\hline
\end{tabular}

CAD, coronary artery diseases; COPD, chronic obstructive pulmonary diseases; CLD, chronic liver disease; CKD, chronic kidney disease; NM, not mentioned; PT, pneumothorax; PM, pneumomediastinum; SE, subcutaneous emphysema; CM, conservative management; ICD, intercoastal drainage tube; $p<0.05$ considered statistically significant; ${ }^{* *}$ Not analyzed further due to reduced frequency of these variables between survivor and nonsurvivor as statistically relevant conclusion could not be derived in further analysis

Table 3: Mode of respiratory support at admission and at time of air leak

\begin{tabular}{lcc}
\hline MODE & Admission & At time of air leak \\
\hline RA & $27(19.9 \%)$ & $24(17.65 \%)$ \\
FM & $10(7.35 \%)$ & $5(3.68 \%)$ \\
NP & $16(11.76 \%)$ & $13(9.56 \%)$ \\
NRBM & $5(3.68 \%)$ & $11(8.1 \%)$ \\
HFNC & $17(12.50 \%)$ & $15(11 \%)$ \\
NIV & $4(2.94 \%)$ & $4(2.95 \%)$ \\
CPAP & $3(2.21 \%)$ & $1(0.74 \%)$ \\
MV & $3(2.21 \%)$ & $35(25.74 \%)$ \\
NM & $51(37.50 \%)$ & $28(20.59 \%)$ \\
\hline RA,
\end{tabular}

RA, room air; FM, face mask; NP, nasal prongs; NRBM, nonrebreathing mask; HFNC, high-flow nasal cannula; NIV, noninvasive ventilation; CPAP, continuous positive airway pressure; MV, mechanical ventilation; NM, not mentioned

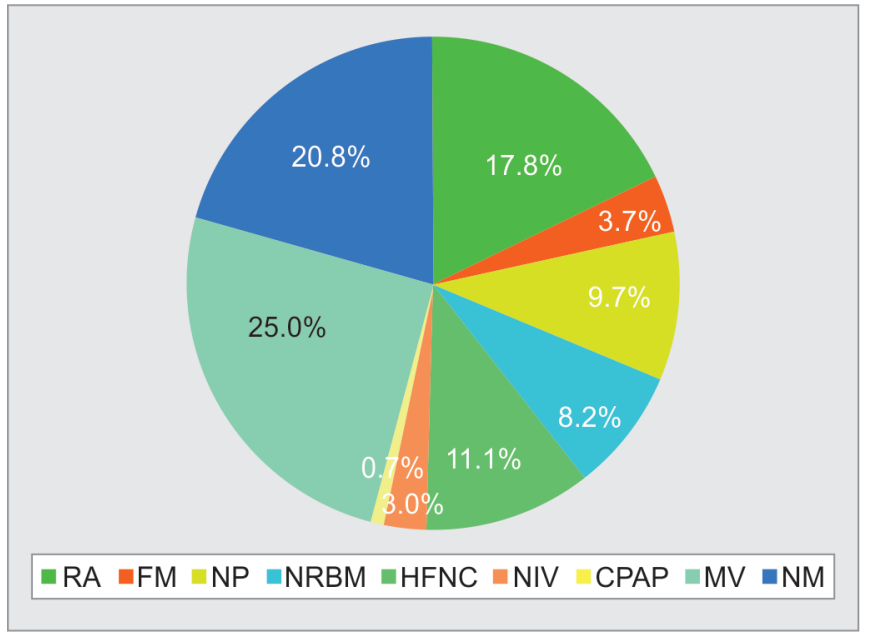

Fig. 3: Relative proportion of respiratory support at time of air leak 
hypertension, and obesity had a higher mortality in subgroup analysis. However, there was no difference in mortality depending upon the presence of comorbidities like diabetes, lung diseases like COPD and asthma, history of smoking, and type of management given i.e., conservative or intercostal drainage tube. The mean duration of stay was 31.37 days and was not significantly different in survivor or nonsurvivor (Fig. 5).

\section{Risk Factors}

According to our study, male sex, age more than 58 years, diabetes, hypertension, high-frequency nasal cannula, and mechanical ventilation are some of the risk factors for COVID-19-related air leak. Our study has shown that $17.65 \%$ of patients have developed spontaneous pneumothorax having no history of any form of oxygen therapy. Significant numbers of patients have developed air leak without any history of comorbidities, and only 11.7 and $12.5 \%$ had the history of preexisting lung disease and history of smoking, respectively.

Further detailed analysis of ventilatory and respiratory mechanics responsible for the development of air leak could not be done as data regarding above-mentioned parameters were lacking.

\section{Discussion}

We did the systematic review of air leak syndrome consisting of pneumothorax, pneumomediastinum, and subcutaneous emphysema in COVID-19 patients and found out that it was associated with high morbidity, mortality, and length of stay.

\section{Demography of Air Leak Syndrome in COVID-19}

In our study, the mean age of COVID-19 patients diagnosed with air leak was 58.44 (SD 14) years but it was higher in nonsurvivor than the survivor $(63.87 \pm 87$ vs $54.40 \pm 14.92, p=0.003)$ showing that the elderly patients diagnosed with air leak are at increased risk of mortality. Though air leak was most common in males $(75.78 \%$ male vs $24.22 \%$ female) but mortality was higher in females $(56.2 \%$ female vs $37.5 \%$ male, $p=0.04)$. Chong et al. in their systematic review of COVID-19 patients with pneumothorax demonstrated that both mean and median age was between 50 and 70 years with male predominance but age was not associated with higher risk of developing pneumothorax. ${ }^{15}$ Similarly, a meta-summary

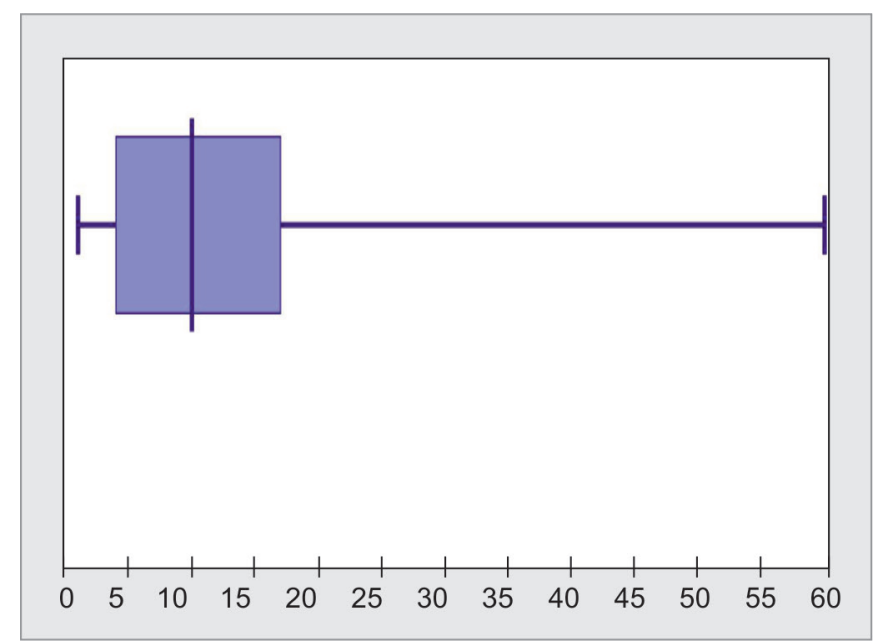

Fig. 4: Box plot representing median number of days of onset of air leak from admission by Nasa et al. on air leak in COVID-19 patients demonstrated that the median age of the patients was 56.02 (SD 15.53) years with $80 \%$ being male. ${ }^{16}$ This is consistent with our findings that elderly male is more susceptible for developing COVID-19 associated air leak syndrome.

\section{Incidence of Air Leak Syndrome in COVID-19}

Chong et al. reported the incidence of pneumothorax to be $0.3 \%$ in hospitalized COVID-19 patients, ${ }^{15}$ which increased up to $12.8 \%$ in critically ill COVID-19 patients requiring mechanical ventilation. ${ }^{4}$ Various authors have reported different incidences of pneumothorax associated with COVID-19 like Miro et al. (0.06\%), Cates et al. (0.6\%), and Ekanem et al. (1.4\%). ${ }^{17-19}$ Wang et al. ${ }^{20}$ in their retrospective analysis demonstrated the incidence of pneumothorax to be $10 \%$ in patients with acute respiratory distress syndrome (ARDS), $24 \%$ in patients receiving mechanical ventilation, and $56 \%$ in patients requiring invasive mechanical ventilation whereas Yang et al. ${ }^{21}$ reported $2.7 \%$ in COVID-19 patients requiring mechanical ventilation. Martinelli et al. in their case series have reported a high incidence of pneumothorax (84.5\%) along with high mortality (88.3\%) in hospitalized COVID-19 patients. ${ }^{22}$ The author has attributed this finding due to the small sample size and critically ill patients requiring a higher form of respiratory support.

\section{Pathophysiology of Air Leak in COVID-19}

In our study, the most common air leak was isolated pneumothorax followed by the presence of all three i.e., pneumothorax, pneumomediastinum, and subcutaneous emphysema. Among these, $25.47 \%$ of patients were receiving mechanical ventilation when diagnosed with air leak suggesting barotraumas as the cause for the air leak. Various ventilatory parameters that contribute to the development of air leak in mechanically ventilated patients consist of amount of tidal volume, peak inspiratory pressure, plateau pressure, positive end-expiratory pressure (PEEP), and respiratory rate. Lungprotective ventilation strategy has been widely used in COVID-19 ARDS patients to prevent barotrauma and air leak. But, Lemmers et al. in their retrospective single-center case-cohort study have reported higher incidence of pneumomediastinum and subcutaneous emphysema in COVID-19 patients on invasive mechanical ventilation despite using the lung-protective ventilation strategy. ${ }^{23}$

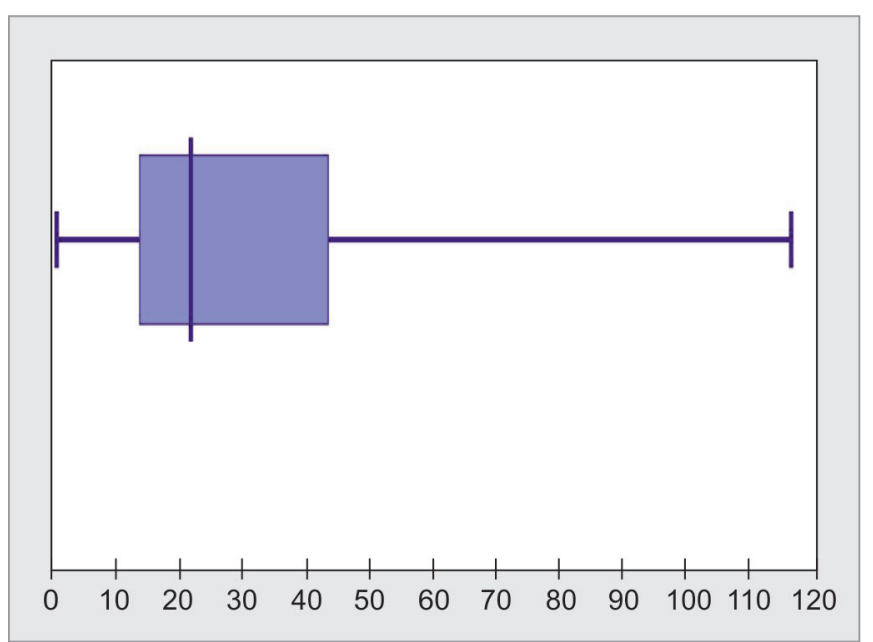

Fig. 5: Box plot depicting median number of stay in hospital of patients with air leak 
Few studies have reported the development of air leaks in even spontaneously breathing COVID-19 patients. A meta-summary by Nasa et al. has demonstrated relatively high number (56.6\%) of patients developing spontaneous air leak. ${ }^{16}$ But, in our study, $17.65 \%$ of the COVID-19 patients developed spontaneous air leak. This finding may be because Nasa et al. have included other leaks like pneumopericardium and pneumoperitoneum in their analysis, which have not been included in our study.

The exact mechanism of development of spontaneous air leak in COVID-19 patients is still unclear. The lung damage in COVID-19 patients is mainly due to dysregulated immune system response to coronavirus resulting in widespread inflammation and finally fibrosis. Postmortem histopathological examination of COVID-19 lung has demonstrated the presence of endothelitis, diffuse alveolar damage, vascular microthrombi, and hyaline formation that is similar to other coronaviruses like severe acute respiratory syndrome (SARS) and Middle East respiratory syndrome (MERS) except the presence of fibro-myxoid exudates that are more common with SARS-CoV-2 infected lung. ${ }^{24}$ The enormous inflammatory response and cytokine release cause alveolar and pleural damage resulting in the weakening of alveolar walls, which leads to the development of dilated and bullous airspace in the lung. The rupture of this airspace during intense coughing or deep spontaneous breathing due to swing in transpulmonary pressure leads to the development of spontaneous air leak. ${ }^{25}$

COVID-19 also leads to the development of nonhomogenous pulmonary parenchyma and decreased lung compliance. This nonhomogenous pulmonary parenchyma results in maldistribution of ventilatory stress as two continuous lung zones with different compliance develop different local stress. The high shear forces along with high respiratory rate due to hypoxemia and self-inflicted lung injury result in the development of pneumothorax.

Another suggested mechanism of developing air leak is the Mecklin effect, resulting in pressure gradient along the bronchovascular bundles. ${ }^{16}$ The momentary rise in interalveolar pressure during intense coughing or deep breathing may rupture the marginal alveoli into the pleural cavity, mediastinum, pericardium, peritoneum, or subcutaneous space.

\section{Risks Factors}

Our study showed that male sex, age more than 58 years, comorbidities like diabetes mellitus and hypertension, and mode of respiratory support like HFNC and mechanical ventilation are some of the risk factors of COVID-19 associated air leak syndrome. Various studies have shown that pulmonary diseases like asthma, COPD, ILD, and bulla along with history of smoking are known risk factors for the development of pneumothorax in sick patients even in the absence of mechanical ventilation. Chong et al. in their systemic review did not show any correlation between preexisting lung disease and the risk of developing pneumothorax among COVID-19 patients. ${ }^{15}$ Similarly, Miro et al. also found no correlation between preexisting lung disease and the development of pneumothorax in nonventilated COVID-19 patients. ${ }^{17}$

In our study, $12.5 \%$ of patients with air leak were associated with smoking, and it was not significant between survivor and nonsurvivor. Multiple studies have shown no association between pneumothorax development in COVID-19 patients and smoking. ${ }^{4,15,17}$ Miro et al. even further demonstrated that nonsmokers were at a 5.5 times increased risk of developing pneumothorax. In circumstances of poor relation between smoking and preexisting lung disease in hospitalized COVID-19 patients, any worsening of respiratory status should prompt the clinician regarding the development of air leak. ${ }^{17}$

\section{Onset of Air Leak in COVID-19}

The overall time to diagnosis air leak in our study was 11.63 $( \pm 10.30)$ days, with no significant difference between survivor and nonsurvivor. Moreover, in our review, we cannot ascertain the duration of noninvasive and invasive mechanical ventilation after which the air leak develops, but $25.74 \%$ of patients were receiving invasive mechanical ventilation (IMV) at the time of diagnosis. Further, we could not report the severity of COVID-19 as the data regarding the severity and ARDS were inconsistent. However, Chong et al. in their systemic review have diagnosed pneumothorax after 9-19.6 days after admission and 5.4 days after IMV..$^{15}$ Abdallat et al. ${ }^{26}$ reported pneumothorax within 3-5 days from IMV while Wang et al. reported that the occurrence of pneumothorax after mechanical ventilation varied from 5 to 37 days. ${ }^{20}$ Nasa et al. have reported the median duration of onset of air leak to be 30 days from admission but have not mentioned median days for onset of air leak after mechanical ventilation. ${ }^{16}$ In COVID-19, the virus mainly affects the lung parenchyma at the periphery and gradually progresses to involve the pleura which possibly explains the onset of pneumothorax at around 10-14 days after symptom onset. ${ }^{27,28}$

\section{Duration of Hospitalization}

In our study, the overall mean duration of hospital stay was 31 days, which was not significant between survivors and nonsurvivors. Mc Guinness et al., Miro et al., and Ekanem et al. have reported prolonged hospital stay among COVID-19 patients diagnosed with pneumothorax than those without pneumothorax. ${ }^{4,17,19}$ Additionally, Miro et al. reported 12.9-, 4.2-, and 15.7-fold increase in the risk of intensive care unit (ICU) admission, prolonged hospitalization, and higher inhospital mortality in patients of pneumothorax with COVID-19 than those without pneumothorax. ${ }^{17}$

\section{Management}

The treatment option for COVID-19 associated air leak depends upon the type of air leak as well as severity of involvement. The treatment option consists of observation (conservative management), intercoastal drainage tube placement, pleurodesis, and surgery. In our study, about $33 \%$ of patients were conservatively managed while $67 \%$ of patients required intercostal drainage tube placement. Currently, there are no recommendations for managing air leak in COVID-19 patients. A small asymptomatic pneumothorax can be managed conservatively with proper monitoring by sequential imaging. A recent trial has found that conservative management was noninferior to interventional management for primary spontaneous pneumothorax. ${ }^{29}$ But, pneumothorax occurring due to positive pressure ventilation in critically ill patients with ARDS needs tube thoracostomy placement.

COVID-19 patients are presenting with persistent air leak (PAL) lasting for more than 5-7 days. Surgical treatment is considered the gold standard for PAL but these patients with ARDS are generally sick and not fit for thoracoscopy and thoracotomy surgery. Pleurodesis with autologous blood has shown promising results in ARDS patients with pneumothorax in reduction of ICU stay, faster weaning, and reduced mortality. ${ }^{30}$

The published literature on thoracotomy or thoracoscopic surgeries for managing ARDS complicated by pneumothorax is extremely limited and needs further research. Huang et al. have demonstrated that extracorporeal membrane oxygenation (ECMO) 
and thoracoscopic surgery can be successfully used for pulmonary bulla resection in severely ill H7N9 patients with refractory pneumothorax and ARDS whereas Wagner et al. showed increased mortality in patients with ARDS and pneumothorax when they underwent thoracotomy. ${ }^{31,32}$

The utility of ECMO for managing pneumothorax has already been reported in the literature. ECMO can be used as an alternative for managing pneumothorax in patients with high ventilator requirements as it helps in reducing the inflammation, overdistension of alveoli, and most important, it helps the lungs to rest. ${ }^{33,34}$

\section{Preventive Strategy}

Lung-protective ventilation strategy has been widely advised and practiced for preventing pneumothorax and air leak in patients with ARDS. It consists of targeting plateau pressure to less than $30 \mathrm{~cm}$ of $\mathrm{H}_{2} \mathrm{O}$ and tidal volume adjusted to predicted body weight. It helps in reducing the alveolar pressure and distension, thus reducing the risk of development of the pneumothorax. Apt use of neuromuscular blockers further reduces the incidence of pneumothorax in severe ARDS patients as it helps in decreasing the negative pressure and shear stress in the pleural cavity. ${ }^{35}$ In patients with rapidly evolving ARDS, early application of ECMO may help in reducing delivered tidal volume, ventilator rate, peak as well as mean airway pressure, oxygen requirement, and acute lung injury, which will further help in reducing the incidence of pneumothorax and mortality. Combes et al. have reported that extracorporeal removal of carbon dioxide (ECCO2R) helps in the application of ultra lung-protective ventilation strategy (tidal volume- $4 \mathrm{~mL} / \mathrm{kg}$ and plateau pressure $<25 \mathrm{~cm}$ of $\mathrm{H}_{2} \mathrm{O}$ ) in patients with moderate ARDS and have found it to be safe and feasible. ${ }^{35}$ Therefore, timely application of $\mathrm{ECCO}_{2} \mathrm{R}$ and ECMO along with lung-protective ventilation strategy may play a key role in the prevention of pneumothorax in critically ill patients with moderate-to-severe ARDS.

\section{Outcome}

The overall mortality in COVID-19 patients with air leak in our study was $40 \%$ but in subanalysis, female gender, age $>60$ years, and patients with comorbidities, like hypertension and obesity, and those receiving mechanical ventilation had higher mortality. However, no significant difference was observed in relation to various comorbidities (diabetes, lung disease, COPD, and asthma), history of smoking, and type of management between survivor and nonsurvivor.

Nasa et al. reported the overall mortality of COVID-19 patients with air leak to be around $31 \%$ which increased to $55 \%$ in patients who have received positive pressure ventilation while it was $23 \%$ in spontaneously breathing patients. ${ }^{16}$ Chong et al. reported the mortality of around $74.2 \%$ in COVID-19 patients diagnosed with pneumothorax while Wang et al. and Martinelli et al. reported mortality of 80 and $88.3 \%$, respectively. ${ }^{15,20,22}$ Martinelli also reported that there was no difference in gender as well as IMV requirement between survivors and nonsurvivors. ${ }^{22}$

\section{Limitation}

Our review has several limitations. First, it included only case reports and case series with significant reporting bias, missing, and incomplete data. Hence, the result cannot be generalized to all COVID-19 patients. Second, the majority of included studies lacked the control arm and the sample size was small. Third, patients with mild COVID-19 infection with undiagnosed pneumothorax may get undetected due to home isolation. Fourth, most studies lacked data regarding ICU parameters (APACHE and SOFA scores, ventilatory settings like $P / F$ ratio, $P E E P$, mode of ventilation, position of ventilation, and respiratory mechanics. Fifth, literature on COVID-19 is changing at a rapid pace; therefore, the result reported in this review may need addition or revision at a later stage.

\section{Conclusion}

Air leak in COVID-19 patients is mainly the manifestation of disease progression resulting in inflammatory insult to lung parenchyma and ventilatory stress-induced alveolar damage. Most of the time, it is responsible for acute worsening of the clinical condition of the patient. It is associated with increased length of stay and mortality especially in the elderly. Many patients have developed spontaneous air leak independent of COVID-19 disease severity, mechanical ventilation, smoking, and lung diseases. Since case reports and case series form the majority of included studies, a well-structured larger cohort study is needed to ascertain the true incidence and outcome of COVID-19 related air leak.

\section{ORCID}

Abhishek Singh (1) https://orcid.org/0000-0002-4690-5118

Yudhyavir Singh $\odot$ https://orcid.org/0000-0002-5101-7609

Neha Pangasa @ https://orcid.org/0000-0003-1131-3478

Puneet Khanna @ https://orcid.org/0000-0002-9243-9963

Anjan Trikha 1 https://orcid.org/0000-0002-6001-8486

\section{References}

1. Ding $X, X u J$, Zhou J, Long Q. Chest CT findings of COVID-19 pneumonia by duration of symptoms. Eur J Radiol 2020;127. DOI: 10.1016/j.ejrad.2020.109009.

2. Yarmus L, Feller-Kopman D. Pneumothorax in the critically ill patient. Chest 2012;141(4):1098-1105. DOI: 10.1378/chest.11-1691.

3. Yao W, Wang T, Jiang B, Gao F, Wang L, Zheng H, et al. Emergency tracheal intubation in 202 patients with COVID-19 in Wuhan, China: lessons learnt and international expert recommendations. $\mathrm{Br} J$ Anaesth 2020;125(1):e28-e37. DOI: 10.1016/j.bja.2020.03.026.

4. McGuinness G, Zhan C, Rosenberg N, Azour L, Wickstrom M, Mason $\mathrm{DM}$, et al. Increased incidence of barotrauma in patients with COVID-19 on invasive mechanical ventilation. Radiology 2020;297(2):E252E262. DOI: 10.1148/radiol.2020202352. PMID: 32614258; PMCID: PMC7336751.

5. Rohailla S, Ahmed N, Gough K. SARS-CoV-2 infection associated with spontaneous pneumothorax. CMAJ 2020;192(19):510. DOI: 10.1503/ cmaj.200609.

6. Sardenberg RA, Sant'Ana JP, Vicente AO, Pereira AS, Bertozzi PV, Mano RB. Recurrent pneumothorax in a COVID-19 patient: a case report. Respiratory Med Case Rep 2020;31:101201. DOI: 10.1016/j. rmcr.2020.101201.

7. Ucpinar BA, Sahin C, Yanc U. Spontaneous pneumothorax and subcutaneous emphysema in COVID-19 patient: case report. J Infect Public Health 2020;13(6):887-889. DOI: 10.1016/j.jiph.2020.05.012. PMID: 32475804; PMCID: PMC7247978.

8. Quincho-Lopez A, Quincho-Lopez DL, Hurtado-Medina FD. Case report: pneumothorax and pneumomediastinum as uncommon complications of COVID-19 pneumonia-literature review. Am J Trop Med Hyg 2020;103(3):1170-1176. DOI: 10.4269/ajtmh.20-0815. PMID: 32705978; PMCID: PMC7470555.

9. Khurram R, Johnson FT, Naran R, Hare S. Spontaneous tension pneumothorax and acute pulmonary emboli in a patient with COVID-19 infection. BMJ Case Rep CP 2020;13(8):237475. DOI: 10.1136/ bcr-2020-237475. 
10. Volpi S, Ali JM, Suleman A, Ahmed RN. Pneumomediastinum in COVID-19 patients: a case series of a rare complication. Eur J CardioThorac Surg 2020;58(3):646-647. DOI: 10.1093/ejcts/ezaa222.

11. Muhammad Al, Boynton EJ, Naureen S. COVID-19 with bilateral pneumothoraces-case report. Respir Med Case Rep 2020;31:101254. DOI: 10.1016/j.rmcr.2020.101254.

12. Ahluwalia AS, Qarni T, Narula N, Sadiq W, Chalhoub MN. Bilateral pneumothorax as possible atypical presentation of coronavirus disease 2019 (COVID-19). Respir Med Case Rep 2020;31:101217. DOI: 10.1016/j.rmcr.2020.101217.

13. Ayazi S, Zebarjadi J, Grubic AD, Tahmasbi H, Ayazi K, Jobe BA. Pneumothorax as the presenting manifestation of COVID-19. J Thoracic Dis 2020;12(12):7488. DOI: 10.21037/jtd-20-1687.

14. Horii T, Fujioka T, Takahashi M, Mori M, Tsuchiya J, Yamaga E, et al. Late-onset pneumothorax in a COVID-19 patient treated with ventilation and ECMO: a case report and literature review. Radiol Case Rep 2020;15(12):2560-2564. DOI: 10.1016/j.radcr.2020.09.036.

15. Chong WH, Saha BK, Hu K, Chopra A. The incidence, clinical characteristics, and outcomes of pneumothorax in hospitalized COVID-19 patients: a systematic review. Heart Lung 2021;50(5):599608. DOI: 10.1016/j.hrtlng.2021.04.005. PMID: 34087677; PMCID: PMC8088235.

16. Nasa $P$, Juneja D, Jain R. Air leak with COVID-19-a meta-summary. Asian Cardiovascular and Thoracic Ann 2021:02184923211031134. DOI: $10.1177 / 02184923211031134$.

17. Miró Ò, Llorens $P$, Jiménez $S$, Piñera $P$, Burillo-Putze $G$, Martín $A$, et al. Frequency, risk factors, clinical characteristics, and outcomes of spontaneous pneumothorax in patients with coronavirus disease 2019: a case-control, emergency medicine-based multicenter study. Chest 2021;159(3):1241-1255. DOI: 10.1016/j.chest.2020.11.013. PMID: 33227276; PMCID: PMC7678420.

18. Cates J, Lucero-Obusan C, Dahl RM, Schirmer P, Garg S, Oda G, et al. Risk for in-hospital complications associated with COVID-19 and influenza-Veterans Health Administration, United States, October 1, 2018-May 31, 2020. Morb Mortal Wkly Rep 2020;69(42):1528. DOI: 10.15585/mmwr.mm6942e3external icon.

19. Ekanem E, Podder S, Donthi N, Bakhshi H, Stodghill J, Khandhar S, et al. Spontaneous pneumothorax: an emerging complication of COVID-19 pneumonia. Heart Lung 2021;50(3):437-440. DOI: 10.1016/j. hrtlng.2021.01.020. PMID: 33631467; PMCID: PMC7846243.

20. Wang XH, Duan J, Han X, Liu X, Zhou J, Wang X, et al. High incidence and mortality of pneumothorax in critically III patients with COVID-19. Heart Lung 2021;50(1):37-43. DOI: 10.1016/j.hrtlng. 2020.10.002. PMID: 33138976; PMCID: PMC7556825.

21. Yang $X, Y u Y, X u$ J, Shu $H$, Liu H, Wu Y, et al. Clinical course and outcomes of critically ill patients with SARS-CoV-2 pneumonia in Wuhan, China: a single-centered, retrospective, observational study. Lancet Respir Med 2020;8(5):475-481. DOI: 10.1016/S22132600(20)30079-5.

22. Martinelli AW, Ingle T, Newman J, Nadeem I, Jackson K, Lane ND, et al. COVID-19 and pneumothorax: a multicentre retrospective case series. Eur Respir J 2020;56(5):2002697. DOI: 10.1183/13993003. 02697-2020.

23. Lemmers DH, Hilal MA, Bnà C, Prezioso $C$, Cavallo E, Nencini N, et al. Pneumomediastinum and subcutaneous emphysema in COVID-19: barotrauma or lung frailty? ERJ Open Res 2020;6(4):00385-2020. DOI: 10.1183/23120541.00385-2020.
24. Wichmann D, Sperhake JP, Lütgehetmann M, Steurer S, Edler C, Heinemann A, et al. Autopsy findings and venous thromboembolism in patients with COVID-19: a prospective cohort study. Ann Intern Med 2020;173(4):268-277. DOI: 10.7326/M20-2003.

25. Elhakim TS, Abdul HS, Romero CP, Rodriguez-Fuentes Y. Spontaneous pneumomediastinum, pneumothorax and subcutaneous emphysema in COVID-19 pneumonia: a rare case and literature review. BMJ Case Rep CP 2020;13(12):239489. DOI: 10.1136/bcr-2020239489.

26. Abdallat M, Khalil M, Al-Awwa G, Kothuru R, La Punzina C. Barotrauma in COVID-19 patients. J Lung Health Dis 2020;4(2). DOI: 10.29245/2689999X/2020/2.1163.

27. Shi H, Han X, Jiang N, Cao Y, Alwalid O, Gu J, et al. Radiological findings from 81 patients with COVID-19 pneumonia in Wuhan, China: a descriptive study. Lancet Infect Dis 2020;20(4):425-434. DOI: 10.1016/ S1473-3099(20)30086-4. PMID: 32105637; PMCID: PMC7159053.

28. Hosseiny M, Kooraki S, Gholamrezanezhad A, Reddy S, Myers L. Radiology perspective of coronavirus disease 2019 (COVID-19): lessons from severe acute respiratory syndrome and middle east respiratory syndrome. AJR Am J Roentgenol 2020;214(5):1078-1082. DOI: 10.2214/AJR.20.22969. PMID: 32108495.

29. Brown SGA, Ball EL, Perrin K, Asha SE, Braithwaite I, EgertonWarburton $\mathrm{D}$, et al. Conservative versus interventional treatment for spontaneous pneumothorax. N Engl J Med 2020;382(5):405-415. DOI: 10.1056/NEJMoa1910775. PMID: 31995686.

30. Martínez-Escobar S, Ruiz-Bailén M, Lorente-Acosta MJ, VicenteRull JR, Martínez-Coronel JF, Rodríguez-Cuartero A. Pleurodesis using autologous blood: a new concept in the management of persistent air leak in acute respiratory distress syndrome. J Crit Care 2006;21(2):209-216. DOI: 10.1016/j.jcrc.2005.10.003. PMID: 16769470.

31. Huang J, Li H, Chen S, Lan C, Lin Q, Weng H. First successful combination of extracorporeal membrane oxygenation (ECMO) with video-assisted thoracic surgery (VATS) of pulmonary bullae resection in the management of refractory pneumothorax in a critically ill patient with H7N9 pneumonia and acute respiratory distress syndrome: a case report. Medicine 2019;98(20):e15661. DOI: 10.1097/MD.0000000000015661.

32. Wagner PK, Knoch M, Sangmeister C, Müller E, Lennartz H, Rothmund $\mathrm{M}$. Extracorporeal gas exchange in adult respiratory distress syndrome: associated morbidity and its surgical treatment. Br J Surg 1990;77(12):1395-1398. DOI: 10.1002/bjs.1800771224.

33. Rozencwajg S, Guihot A, Franchineau G, Lescroat $M$, Bréchot $N$ Hékimian $\mathrm{G}$, et al. Ultra-protective ventilation reduces biotrauma in patients on venovenous extracorporeal membrane oxygenation for severe acute respiratory distress syndrome. Crit Care Med 2019;47(11):1505-1512. DOI: 10.1097/CCM.0000000000003894.

34. He H, Wang H, Li X, Tang X, Wang R, Sun B, et al. Successful rescue combination of extracorporeal membrane oxygenation, highfrequency oscillatory ventilation and prone positioning for the management of severe methicillin-resistant Staphylococcus aureus pneumonia complicated by pneumothorax: a case report and literature review. BMC Pulm Med 2017;17(1):1-8. DOI: 10.1186/s12890-017-0445-z.

35. Combes A, Fanelli V, Pham T, Ranieri VM, Investigators. ESOI feasibility and safety of extracorporeal $\mathrm{CO}_{2}$ removal to enhance protective ventilation in acute respiratory distress syndrome: the SUPERNOVA study. Intensive Care Med 2019;45(5):592-600. DOI: 10.1007/s00134019-05567-4. 